\title{
The politics and analytics of health policy
}

\author{
Calum R. Paton ${ }^{1 *}$
}

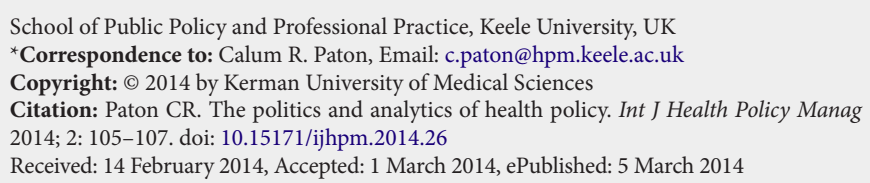

\section{Introduction}

Let us start with an example of health policy analysis in action. Within that category of countries loosely known as 'the West', quite basic differences exist in attitudes to health policy and also actual health policy. Comparing the US with mainland Europe and indeed Canada, for example, one perceives a difference in attitude on the part of the majority towards collectivism and individualism in access to, provision of and financing of healthcare. The explanation for policy and system differencesfor example, between the US healthcare system(s) and the various NHSs of the UK countries (England, Scotland, Wales and Northern Ireland) - is commonly framed in terms of 'ideology' but there are also 'institutional' explanations (1). Additionally, however, popular attitudes or 'values' may be taken as autonomous 'inputs' into the explanation (e.g. 'American values prevent the enactment of an NHS') or, at least in part, derived from or influenced by institutional reality. If, for example, there is no chance of a bill to establish an NHS or a comprehensive system of public health insurance passing in Washington, then reformers over time trim not only their legislative ambitions, but also their very way of thinking about the issue.

In this case, what we might be observing is the interplay of ideas and institutions (2): ideas about what is possible are influenced over time, and that can-over an even longer period of time-lead to those ideas coalescing into an 'ideology' of what is desirable (i.e. politics as the art of the possible, where the practitioners eventually internalise the possible as the (most) desirable state-of-affairs). Institutions shape ideology. And conversely, ideology can shape institutions: approaches to change (e.g. incremental versus comprehensive; marginal versus radical) can affect how politicians and other actors behave within political institutions, and whether they accept the standard-operating procedures or challenge them.

Policy analysis may be descriptive and analytical (positive as opposed to normative, in the language of economics) - what policy do we see, and why? Alternatively it may be normative -what policy do we wish to see and how can we get it? In a separate but related vein, health policy for some will tend to be studied with overtones of 'positivism' (which I will define here as seeking patterns in data without necessarily explaining them at the level of human perception and action), whereas for others it will involve a rich range of 'policy studies' involving things like who holds power, what the structures are, which condition (and possibly 'bias') decision-making and the emergence of policy, and how implementation is affected by behavioural as well as 'technical' factors.

\section{Health policy and politics}

My own perspective is that policy is a reflection of politics and that to study health policy is to study the politics of public policy as applied to health. This perspective sees health policy as part of political science, drawing upon sociology and other social sciences, but not seeing any of these in too autarchic terms. Furthermore, this perspective may see health policy as not only being derived from prevailing politics, but also as helping to constitute the nature of politics. To give an example of what this may mean, Moran's term 'the healthcare state' points to what he calls the 'mutual embeddedness' of healthcare and the state (3). The state influences the nature of the healthcare system(s) and trends within the healthcare system (for example, the demands for healthcare made by powerful or pivotal groups) influence the (changing) nature of the state and of politics more generally (i.e. society-wide).

For some, policy is 'management' as opposed to management being the derivative of policy (i.e. its application, both in implementation and in the running of 'the system' postimplementation). Here, on the one hand, we may detect the influence of the 'new public management', and the alleged supercession of the 'old' public administration. Politics has reached the 'end of ideology' — not in Bell's (4) sense of a socialdemocratic compromise between Western capitalism and Soviet 'communism' as seen from a vantage point at the end of the 'first' Cold War of the 1950s, but in the sense that 'we are all capitalists now', a stance often disguised as the seemingly more neutral statement that the scope of politics is diminished by allegedly inexorable trends in the nature and role of the 'modern state'. In what might have been called 'the advanced Western capitalist state' in the 1960s and 1970s, we are seeing since the 1980s or 1990s the decline of politics as ideological choice and the diminution of politics to choice amongst different tribes of technocrats using different discourse for their core party support from that which they use to the centre-ground, and which constrains their policy when and if elected.

And it is not too fanciful to see the 'ideological closure' in core capitalist countries around neo-liberal health policy options as reflecting a reality which is welcome to some and pragmatically-accepted by others. In this connection, we may note that England is a core capitalist country (where the dominant health policy discourse is now of the market, and 'insider' networks, including supposedly 'neutral' institutes, do not challenge this) and the other UK countries, on the periphery, overtly reject such a discourse. 
Health policy and social science

Firstly, the so-called positivist or 'quantitative' approach is not, or should not be, a methodology for studying human behaviour, but something rather different-a tool for e.g. allowing correlations to be observed, investigated further and issues of causality tentatively hypothesized. Secondly, to investigate such a hypothesis further, human behaviour will probably have to be researched using 'qualitative' means of research. But these camps become polarised when positivism is practised without acknowledging the need for complementary explanation; and when 'anti-positivism' dissolves into the unhelpful relativism that there is 'no such thing as truth'.

Correlations without causality are dangerous. Inversely, the stance that each observer has his own truth is compelling but misleading: to argue that all truth is based on the eye of the beholder, and to see social 'truth' as constructed as if in a negotiation rather than a discovery, ignores the fact that there is a domain of material reality. The indeterminacy of human action (e.g. over space and time) is not the same as saying that different observers cannot observe the same thing at the same time, in the same place. Where interpretivism has its own realm is where the study of human perception, emotion, motivation, and intention is needed to explain action, or the effect of the former upon the latter.

In health policy, the 'extreme positivist' approach has been exemplified recently by research in England which has been used to argue that market forces are beneficial in public healthcare systems on the basis that 'competition saves lives' (5). Without denying that statistical correlations have been achieved, it is difficult to suggest without a further complementary, but different type of research that the hypothesis has been proved. There are many reasons why this is not the case, and that 'health policy' conclusions drawn from uni-disciplinary, deductive research are flawed and quite possibly irresponsible (6).

\section{Health policy: less bold but wiser?}

Insight into the evolution of health policy is gained by tracing its historical link to healthcare system evolution-again, chicken or egg? As systems developed in the direction of socialization, in Europe, Canada, Australasia, certain Latin American countries and (derivatively) in certain African and Asian colonies, the characteristics they acquired led to seminal studies in sociology and political science which sought to explain. Later, the era of conservative retrenchment and privatization led to further theorisation. Predictably, there have attempts to 'over-theorise' each of these epochs, usually allied to giving too much credence to the more apocalyptic claims about what is happening in the real world (e.g. progressive reform in the 1960s and 1970s claimed to be the wave of the future; conservative reaction from the 1980s claimed to have destroyed the welfare state and globalisation suggested to make equitable healthcare systems impossible in individual nation-states).

The reality is inevitably more messy in practice and complex in theory. For example, it was always unlikely that there was one organisational fix to achieve (for example) the aims of progressive reformers in the health policy arena who wish healthcare to be comprehensive, universal and free-at thepoint-of-use. There are better and worse Beveridge systems and better and worse Bismarckian systems (7). Some of each focus minimally upon security, possible for ethical reasons, more likely for conservative reasons. Some of each are more ambitious, seeing access to affordable healthcare for all as part of human or at least citizen rights and part of enabling individuals to flourish through collective financing and possible provision. Equally, conservative trends on a global basis do not lead to uniform retrenchment or similar reforms in countries across the world. In a similar spirit, one should note, for example, that attempts to achieve similar goals in different healthcare systems should not be based upon 'organisational copy-cattism', which may include what Marmor calls 'fads, fallacies and foolishness in medical care policy and management' (8). Do not be fooled or dismayed by Marmor's use of the term 'medical' as opposed to 'health': it is surely a virtue to imply that, while health in the wider sense depends upon much beyond the reach of medical care, most 'healthcare systems' are mostly medical care systems and it may be naive to assume that such systems should take on the burden of promoting health on an equitable basis (i.e. should be held responsible for sweeping up the detritus produced by economic inequality and its consequences, social deprivation, and environmental despoliation on an inegalitarian basis). Instead wider economic and social policy should shoulder that burden.

\section{Inter-disciplinary study}

Let us consider a classic 'inter-disciplinary study'-by an economist who was interested in political science, Albert Hirschman (9). His famous study, Exit, Voice and Loyalty is not about health policy at all. Hirschman was interested in what happened when consumers, citizens or party-members sought to influence their providers, government or party; and what happened when company owners, employees, the state or party decision-makers reacted to market conditions, incentives or such influence of whatever sort from consumers of whatever sort. Influence was conceptualised in terms of 'exit', which we might term market choice of provider; 'voice', which we might term a desire to be a stakeholder with a preferred or 'one's own' provider rather than abandon it; and 'loyalty', which is a value in possible conflict with the user's desire for improvement of one sort or another.

Hirschman showed what happened (for example) when certain 'theoretical' assumptions were pragmatically, realistically, or hypothetically relaxed; when monopoly providers were 'lazy' ('satisficing' and making 'enough' profit rather than maximising and producing 'super-normal' profits); when market choice worked 'too quickly' to allow providers to improve; when providers could survive by specialising in monopoly 'niches' rather than seeking to improve quality as a result of consumer/ user pressure; and so on. It is instructive to apply his approach to the health sector, as I have suggested with 'market reform' in the English NHS $(10,11)$.

In a broader sense, Hirschman demonstrates by example the sort of analysis necessary, on the one hand, when the 'ideal type' assumptions of different disciplines are relaxed one-by-one and/or, on the other hand, when core assumptions drawn from different disciplines are selectively brought together (which may amount to the same thing).

If we are interested in getting beyond sterile conflicts (or worse, mutual ignorance) between academic disciplines, then this type of approach is promising in helping us to understand why often unexpected things happen. And if we have values which we wish to promote in undertaking health reform, then political 
studies help us understand the scale of the task we face.

Acknowledgements

This Editorial draws in part upon an article for Health Economics, Policy and Law (Cambridge University Press, UK), Vol. 8, 3 (2013), 'Disciplining health policy'.

Ethical issues

Not applicable.

Competing interests

The author declares that he has no competing interests.

Author's contribution

CRP is the single author of the manuscript.

\section{Endnotes}

${ }^{1}$ Professor Calum Paton is the Editor-in-Chief of International Journal of Health Planning and Management (Wiley Blackwell Publishers).

\section{References}

1. King A . Ideas, institutions and the policies of governments. $\mathrm{Br} J$
Polit Sci 1973; 3: 291-313.

2. Paton CR. U.S. Health Politics: Public Policy and Political Theory. Aldershot and New York: Avebury; 1990.

3. Moran M. Governing the Healthcare State. Manchester: Manchester University Press; 1999.

4. Bell D. The End of Ideology. New York: Basic Books; 1960.

5. Cooper Z, Gibbons S, Jones S, McGuire A. Does hospital competition save lives? Evidence from the English NHS. The Economic Journal 2011; 121: F228-60.

6. Greener I. Unpacking the evidence on competition and outcomes in the English NHS. J Health Serv Res Policy 2012; 17: 193-4.

7. Paton CR. The Impact of Market Forces on Health Systems: A Review of Evidence in the 15 European Union Member States. Dublin: European Health Management Association; 2000.

8. Marmor T. Fads, Fallacies and Foolishness in Medical Care Policy and Management. New Jersey: World Scientific; 2009.

9. Hirschman A. Exit, Voice and Loyalty. Cambridge, Ma: Harvard University Press; 1970.

10. Paton $\mathrm{CR}$. Visible hand or invisible fist? The new market and choice in the English NHS. Health Econ Policy Law 2007; 2: 31725.

11. Paton CR. New Labour's State of Health: Political Economy, Public Policy and the NHS. Aldershot: Ashgate; 2006. 